\title{
Hypothyroidism and Heart Failure: Epidemiology, Pathogenetic Mechanisms \& Therapeutic Rationale
}

Jonathan Francois, Mohammed Al-Sadawi, Joseph Casillas, Evan Botti, Lina Soni, Debora Ponse, Scarlett Maria Decamps, and Samy I. McFarlane* $^{*}$

Department of Medicine, SUNY-Downstate Health Science University, Brooklyn, New York, USA

\section{Abstract}

Heart Failure (HF) is a major public health problem and a major cause of morbidity and mortality worldwide. Thyroid hormones (TH) have multiple effects on the heart and cardiovascular system. In recent years, studies have shown that hypothyroidism, including subclinical hypothyroidism, is associated with an increased risk for developing and worsening of HF. This review addresses the relationship between HF and hypothyroidism by highlighting the epidemiology, pathophysiology and management.

\author{
Publication History: \\ Received: March 25, 2020 \\ Accepted: May 30, 2020 \\ Published: June 01, 2020

\section{Keywords:} \\ Heart failure, Hypothyroidism, \\ Subclinical hypothyroidism, \\ Pathogenesis
}

\section{Introduction}

Heart failure (HF) is a clinical syndrome characterized by structural and/or functional impairment of ventricular filling or ejection of blood resulting in insufficient perfusion to meet metabolic demands. There is no single diagnostic test for HF, it is a clinical diagnosis based on history, physical examination, laboratory and imaging parameters [1]. Thyroid hormones (TH) have numerous effects on body systems, especially the heart and cardiovascular system including effects on the relaxation and contractile properties of the heart and are critical in preserving cardiac structure [2]. In recent years, studies have shown that alterations in $\mathrm{TH}$ are associated with a wide spectrum of cardiovascular diseases - specifically, hypothyroidism and subclinical hypothyroidism have been reported to be associated with increased incidence and worsening of HF, with and without underlying heart disease $[3,4]$. The aim of this review is to evaluate the effects of hypothyroidism and subclinical hypothyroidism. We will also discuss the postulated mechanisms that may induce and/or exacerbate HF and highlight the appropriate management strategies.

\section{Prevalence of Decrease T3/HF/Subclinical and Associations (Prevalence of Hypothyroidism/Subclinical Hypothyroidism in $\mathrm{HF}$ )}

Nearly 10 million people (4.6\%) in the United States have hypothyroidism. Most of them are asymptomatic, i.e. with subclinical hypothyroidism (4.3\%). In iodine-replete communities, the prevalence of spontaneous hypothyroidism is between 1 and $2 \%$, and it is 10 times more common in women than in men, and particularly prevalent among older women. Studies in Northern Europe, Japan and the USA have found the prevalence to range between 0.6 and 12 per 1000 women and between 1.3 and 4.0 per 1000 in men investigated [5].

Tunbridge et al. conducted a study in Whickham, England to determine the prevalence of thyroid disorders in the community and reported that $7.5 \%$ of women and $2.8 \%$ of men of all ages had thyroid stimulating hormone (TSH) levels greater than $6 \mathrm{mlU} / \mathrm{L}$. After reviewing 12 studies across different cultures, the Whickham study concluded that primary thyroid gland failure $(\mathrm{TSH}>6 \mathrm{mlU} / \mathrm{L})$ is 5\% in multiple populations [6]. Moreover, in the Colorado Thyroid Disease Prevalence Study, 9.4\% of the subjects had a high-serum TSH concentration, of whom $9.0 \%$ had subclinical hypothyroidism [7]. Among those with an elevated serum TSH concentration, 74\% had a value between 5.1 and $10 \mathrm{mlU} / \mathrm{l}$ and $26 \%$ had a value $>10 \mathrm{mlU} / \mathrm{l}$. Women had a higher percentage of high serum TSH concentration versus men in each decade of age, and ranged from 4 to $21 \%$ in women and 3 to $16 \%$ in men.

The National Health and Nutrition Examination Survey, composed of 4392 participants conducted between 1999-2002, noted a 3.7\% prevalence of hypothyroidism in the general population. It also demonstrated that the serum TSH concentrations increased with age in both men and women and were higher in whites than in blacks, independent of serum anti-thyroid antibody concentrations $[8,9]$.

Heart failure (HF) has been considered an epidemic and a global health problem, with a prevalence of over 5.8 million in the USA and over 23 million worldwide [10]. The estimates of HF prevalence in developed countries generally range from $1-2 \%$ of the adult population [11]. Although the age-adjusted incidence and prevalence of HF are decreasing, the absolute number of patients with HF has drastically increased, secondary to shifts in the global age distribution, increased life expectancy, medical advancement and general population growth [12]. HF incidence has shown signs of stabilization and possible reduction in developed countries based on community-based cohorts, such as Framingham and Olmstead county $[13,14]$. However, the incidence of HF varies between ethnic groups in the USA. The Multi-Ethnic Study of Atherosclerosis reported the highest incident rates of $\mathrm{HF}$ among African-American individuals, intermediate rates among Whites and Hispanic individuals, and the lowest rates among Chinese-American individuals [15].

*Corresponding Author: Prof. Samy I. McFarlane, College of Medicine Department of Medicine, Division of Endocrinology, Internal Medicine Residency Program Director, State University of New York, Downstate Medical Center, 450 Clarkson Ave, Box 50, Brooklyn, New York, USA, Tel 718-270-6707, Fax 718-2704488; E-mail: smcfarlane@downstate.edu

Citation: Francois J, Al-Sadawi M, Casillas J, Botti E, Soni L, et al. (2020) Hypothyroidism and Heart Failure: Epidemiology, Pathogenetic Mechanisms \& Therapeutic Rationale. Int J Clin Res Trials 5: 146. doi: https://doi. org/10.15344/2456-8007/2020/146

Copyright: (c) 2020 Francois et al. This is an open-access article distributed under the terms of the Creative Commons Attribution License, which permits unrestricted use, distribution, and reproduction in any medium, provided the original author and source are credited. 
Citation: Francois J, Al-Sadawi M, Casillas J, Botti E, Soni L, et al. (2020) Hypothyroidism and Heart Failure: Epidemiology, Pathogenetic Mechanisms \& Therapeutic Rationale. Int J Clin Res Trials 5: 146. doi: https://doi.org/10.15344/2456-8007/2020/146

Page 2 of 5

Ning et al. conducted a meta-analysis including 19,354 subjects with HF, 2173 with hypothyroidism, to clarify the association of hypothyroidism and all-cause mortality and morbidity in patients with HF. The analysis reported that hypothyroidism and subclinical hypothyroidism were associated with increased all-cause mortality even after correction with thyroid replacement therapy. Moreover, hypothyroidism and subclinical hypothyroidism were associated with increased risk of hospitalization in HF patients [3].

\section{Pathophysiology of Decrease T3 and Effect on HF}

The American College of Cardiology defines HF as a complex clinical syndrome that impairs the ability of the ventricle to fill with or eject blood [16]. In recent years, studies have shown that untreated overt hypothyroidism is an important cause of HF [3,17]. Moreover, persistent subclinical hypothyroidism has been associated with the development of $\mathrm{HF}$ in patients with and without underlying heart disease [18].

Thyroid gland produces and releases hormones mostly as the prohormone thyroxine (T4). triiodothyronine (T3), the biological active thyroid hormone, derives from the conversion of T4 by deiodinase enzymes. Three deiodinase enzymes regulate circulating and tissue concentration of THs: type 1 (D1); type 2 (D2), and type 3 (D3). D1 is considered the major peripheral source of circulating T3 and is commonly found in the liver and the kidney, whereas D2 plays a critical role in providing local conversion to T3in the heart, skeletal muscles, brain and pituitary tissues. D3 is involved in the inactivation and degradation of T3 [19]. Due to the necessity of T3 in preserving both cardiac morphology and performance in adult life, the heart is sensitive to reductions in local $\mathrm{T} 3$ levels.
Genomic nuclear effects of thyroid hormones initiate most of physiologic effects in humans. T3 binds to specific nuclear thyroid hormone receptors (TRs), which subsequently bind as homodimers or heterodimers to thyroid hormone response elements in the promoter region of some genes [20-22]. There are two isoforms of receptors generated by two TR genes in the heart. TRa1 transcripts binds to T3 with high affinity and acts as a positive regulator, whereas TRa2 acts as a negative regulator as it binds TREs but does not bind to T3 [20-23].

There are many cardiac structures that are transcriptionally regulated by T3, such as sarcoplasmic reticulum calcium ATPase (SERCA2), alpha - myosin heavy chain ( $\alpha \mathrm{MHC}$ ), B1 adrenergic receptors sodium/ potassium ATPase, voltage-gated potassium channels, malic enzyme and atrial and brain natriuretic hormone [20,21]. Other cardiac genes are negatively regulated by $\mathrm{T} 3$ namely $\beta \mathrm{MHC}$, phospholamban, sodium/calcium exchanger, TRa1 and adenylyl cyclase type $\mathrm{V}$ and VI [20-21]. However, T3 also has non genomic effects on cardiac myocyte and peripheral vascular resistance. These effects involve the transport of ions across the plasma membrane, glucose and amino acid transport and mitochondrial function $[21,23]$.

The effects of T3 allow it to have control on the inotropic and lusitropic properties of the myocardium and have an influence on cardiac growth, myocardial activity and vascular function. As a result, thyroid hormone deficiency is likely responsible for an increased risk of HF events, by causing cardiac atrophy, chamber dilation and impaired myocardial blood flow. (Figure 1)

Cases of hypothyroidism and reversible dilated cardiomyopathy have been reported. Changes in aMHC expression by measuring mRNA, extracted from endomyocardial biopsy, of a hypothyroid

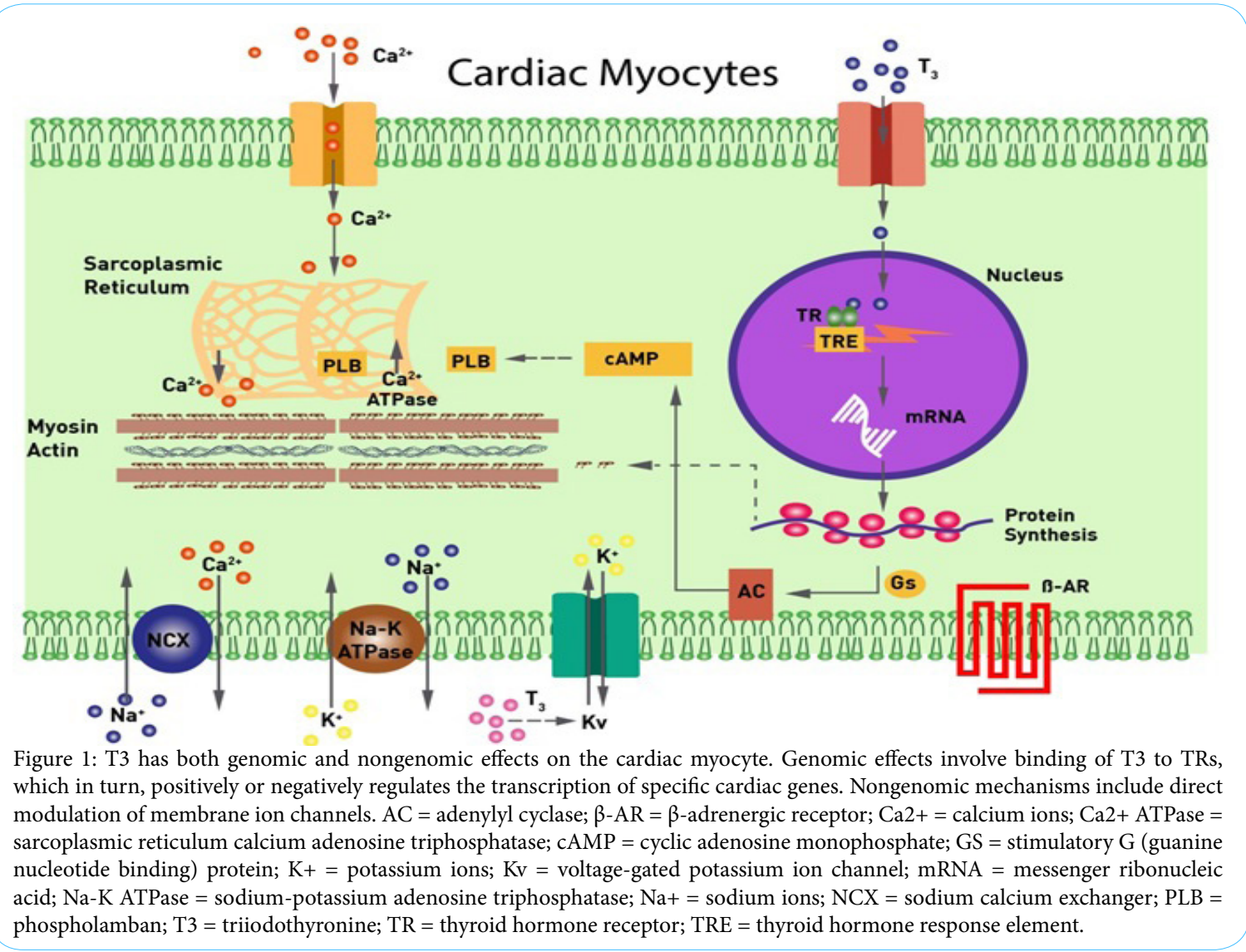


Citation: Francois J, Al-Sadawi M, Casillas J, Botti E, Soni L, et al. (2020) Hypothyroidism and Heart Failure: Epidemiology, Pathogenetic Mechanisms \& Therapeutic Rationale. Int J Clin Res Trials 5: 146. doi: https://doi.org/10.15344/2456-8007/2020/146

Page 3 of 5

patient with dilated cardiomyopathy before and after T4 replacement therapy. The administration of thyroid hormone therapy and restoration of euthyroidism produced an increase in aMHC gene expression and reversed the cardiomyopathy [24].

\section{Relation of Decreased T3 and Other Heart Diseases}

The total thyroid hormones produced by the thyroid gland is $80 \%$ thyroxine (T4) and $20 \%$ triiodothyronine (T3), however the concentration of T3 in the plasma is 1/40 of T4. Thyroxine has an intrinsic effect whereas T3 is necessary for all metabolic activities and used by all organs. In general, the effects of low T3 are essentially the opposite of hyperthyroidism, with indirect and direct effects on the heart (Table1) $[20,1]$. In the previous section the effects of Hypothyroidism on heart failure were explained. In this section we will focus on the effects of low T3 on the cardiovascular system other than heart failure.

\begin{tabular}{|l|}
\hline Indirect Effect on Cardiovascular Function \\
\hline Mild hypertension \\
\hline Narrowed pulse pressure \\
\hline High serum concentrations of cholesterol \\
\hline High serum concentrations of creatininekinase (specifically CK-MM) \\
\hline Pericardial effusions \\
\hline Non-Pitting edema (myxedema) \\
\hline Cardiac arrhythmias (Torsade de pointes) \\
\hline Accelerated atherosclerosis and coronary artery disease \\
\hline Increased carotid intimal thickening \\
\hline Impaired endothelial-dependent vasodilation \\
\hline Direct Effect on Cardiovascular Function \\
\hline Increase systemic vascular resistance \\
\hline Decrease heart rate \\
\hline Decrease ejection fraction \\
\hline Decrease cardiac output \\
\hline Increase isovolumetric relaxation time \\
\hline Decrease blood volume \\
\hline Table 1: Effects of Low Triiodothyronine (T3) and on the Cardiovascular \\
system. \\
\hline
\end{tabular}

The major changes of low T3 on the cardiovascular system are related to decreased cardiac output, cardiac contractility, bradycardia, and increased peripheral vascular resistance. But many other atherosclerotic modifiable risk factors like high concentrations of cholesterol; accelerated atherosclerosis, coronary artery disease and impaired endothelial derived relaxation factor (nitric oxide) are also affected $[25,26]$. Systemic vascular resistance can increase as much as $50 \%$ due to the decrease in arterial compliance [26,27]. In hypothyroidism, as opposed to hyperthyroidism, atrial arrhythmias are rare and ventricular ectopy is common [26]. Low T3 levels by regulatory effects on the expression of numerous ion channels in the heart (B-adrenergic, Na/K ATPase, Voltage-gated K channels, Na/Ca exchanger etc.) $[28,29]$, tend to prolong the cardiac action potential and hence the QT interval. Consequently, attenuated activity on precordial examination if often appreciated predisposes the patient to ventricular irritability and, in rare cases, acquired torsade de pointes [30].

\section{Effect of Treating Hypothyroidism in Heart Failure}

Hypothyroidism is a reversible cause of HF. Consequently, thyroid function should be evaluated in patients with HF and non-ischemic dilated cardiomyopathy. The American College of Cardiology guidelines for HF recommend screening for serum thyroid hormones levels for all newly diagnosed HF patients [16]. Hypothyroidism has many effects on the heart's physiology and internal blood supply. Studies have shown the administration levothyroxine (LT4) can actually reverse myocyte apoptosis, improve cardiovascular performance and ventricular remodeling in hypothyroidism [3,31]. Moreover, diastolic dysfunction, impaired ventricular filling and coronary flow improve when euthyroidism is restored. The Cardiovascular Health Study demonstrated that LT4 may decrease the risk of developing heart failure in patients with subclinical hypothyroidism (SHypo) and $\mathrm{TSH}>10$ [4]. Consequently, it appears that replacement doses of LT4 should be considered in patients with SHypo and TSH $>10 \mathrm{mU} / \mathrm{l}$ to prevent the risk of developing HF.

Additionally, thyroid hormone replacement has been shown to decrease total cholesterol, low-density lipoproteins (LDL) and triglycerides, reduce blood pressure, improve diastolic function, and control heart rate both at rest and during exercise. These documented effects all contribute to a theoretical risk reduction in developing atherosclerosis $[20,24,32,33]$.

However, a problem that many physicians encounter is the fact that hormonal therapy may precipitate both fatal arrhythmias and/ or myocardial ischemic events. Per Somwary et al., 20\% of patients with hypothyroidism maybe over treated during replacement therapy leading to increased risk of atrial fibrillation, especially among the elderly [34,35].

Hence, the usual approach (start low, go slow) is to start with the lowest dose of levothyroxine and titrate up until a euthyroid state has been achieved. Despite the improvement in both symptoms and cardiac contractility, close observation is needed when starting thyroid hormonal therapy, particularly in elderly and in those with known coronary ischemia [36,37].

\section{Effect of Subclinical Hypothyroidism on Heart Failure and the need for Therapy?}

Subclinical hypothyroidism is a biochemical diagnosis; it is defined as a normal T4 concentration while also having an elevated serum TSH concentration. Many patients usually do not have any symptoms; therefore, it is merely considered a laboratory diagnosis. Its prevalence ranges from 4 to 15 percent in the United States [18]. There have been prospective studies suggesting that the annual rate of progression to overt hypothyroidism ranges from 2 to 4 percent depending on the initial TSH level. Higher TSH levels have been associated with increased cardiovascular disease including heart failure and coronary heart disease. There is some discrepancy about the exact levels related to increased risk, but the general consensus is that levels greater than $10 \mathrm{mU} / \mathrm{L}$ are associated with more cardiovascular pathology. The Cardiovascular Health Study revealed that patients with a TSH equal or greater than $10 \mathrm{mU} / \mathrm{L}$ had an increased risk of $\mathrm{HF}$ and a greater baseline peak $\mathrm{E}$ velocity, which is a measurement of diastolic function associated with HF incidence, after adjustment for age, gender, and systolic blood pressure compared to euthyroid participants [4]. However, patients with TSH 4.5 to $9.9 \mathrm{mU} / \mathrm{l}$ had no increased HF risk. Increased LV mass, impairment of LV relaxation 
Citation: Francois J, Al-Sadawi M, Casillas J, Botti E, Soni L, et al. (2020) Hypothyroidism and Heart Failure: Epidemiology, Pathogenetic Mechanisms \& Therapeutic Rationale. Int J Clin Res Trials 5: 146. doi: https://doi.org/10.15344/2456-8007/2020/146

Page 4 of 5

were also exclusively associated with subclinical hypothyroidism with TSH $>10.0$ [4]. The Health Aging and Body Composition populationbased study showed that patients (aged 70-79 years) with TSH level $7 \mathrm{mU} / \mathrm{l}$ or greater had a higher rate of $\mathrm{CHF}$ incidence and recurrence compared with euthyroid patients. Among the 127 patients who had HF, 51 had recurrent HF events [38]. Furthermore, in the PROSPER study patients with persistent SHypo had an increased rate of HF hospitalization compared with euthyroid controls with an age- and sex-adjusted HR of 4.99 (95\% CI, 1.59-15.67) [39].

When treating a patient with heart failure, that is also found to have subclinical hypothyroidism, there are many discrepancies in regards to starting treatment with levothyroxine. Some studies showed beneficial outcomes when treating with hormone replacement, including decreased blood pressure, LDL, total cholesterol and carotid intima thickness [40]. But other studies have shown no significant reduction on CAD [41]. On the contrary, analysis from a population based cohort study has linked increased cardiovascular mortality in terms of ischemic heart disease and dysrhythmias in patients treated for subclinical hypothyroidism with levothyroxine. This trend has been seen mainly in elderly patients ( $>70$ years old). After the European Thyroid Association proposed guidelines in regards to this matter, there has been a general consensus to treat with levothyroxine all those patients $<70$ years old who have a TSH serum concentration $>10 \mathrm{mIU} / \mathrm{L}$. For patients $>70$ years old with TSH levels $<10 \mathrm{mIU} / \mathrm{L}$ the guidelines discourage from treating, given higher chances of exacerbating ischemic events and arrhythmias in CAD patients [42].

Studies show that 7 out of 10 elderly women will have subclinical hypothyroidism with nearly the same changes in cardiovascular function, but less marked, than overt hypothyroidism [43]. A study performed in Netherlands comprised of 1149 postmenopausal women demonstrated women with subclinical hypothyroidism where more likely to have a myocardial infarction and a higher frequency of calcification to the aorta [44]. When patients with subclinical hypothyroidism are treated with thyroxine, systolic and diastolic cardiac function improves [45]. Nevertheless, screening and management strategies are still a subject of disagreement, but from the cardiac perspective, treating a patient with high serum thyrotropin and normal serum thyroid hormone concentration, seems to offer a benefit with minimal risks $[46,47]$.

At the present time, there is no randomized clinical trial evaluating the long-term cardiovascular outcomes in patients with subclinical hypothyroidism receiving hormonal replacement with levothyroxine. Further studies are needed to inform guidelines when encountering these patients, especially in the elderly population $>65$ years old.

\section{Conclusion}

In this review, we outlined the epidemiology and the relationship between hypothyroidism and heart failure. We also discussed the pathogenetic mechanisms by which thyroid hormone, directly and indirectly influences cardiac function. Furthermore, we highlighted the rationale for therapy with $\mathrm{T} 4$, particularly in those with $\mathrm{TSH}>10 \mathrm{mU} / \mathrm{l}$

It is clear that both overt and subclinical hypothyroidism can have varied but profound effects on cardiac hemodynamics and physiology contributing to cardiac related morbidities. While the cardiovascular effects of subclinical hypothyroidism are clear, the current management guidelines are still debated. Currently, very high
TSH levels in an asymptomatic patient are generally treated, but less definitive data is available regarding initiation of therapy. It is also important to note that close monitoring is recommended especially in the elderly. Overall, there is evidence to suggest that treatment of subclinical hypothyroidism can improve cardiovascular outcomes; however, randomized controlled clinical trials in this field are lacking and warranted.

\section{Competing Interests}

The authors declare that they have no competing interests.

\section{Acknowledgement}

This work is supported, in part, by the efforts of Dr. Moro O. Salifu M.D., M.P.H., M.B.A., M.A.C.P., Professor and Chairman of Medicine through NIH Grant number S21MD012474.

\section{References}

1. Yancy CW, Jessup M, Bozkurt B, Butler J, Casey Jr D, et al. (2013) 2013 ACCF/AHA guideline for the management of heart failure: a report of the American College of Cardiology Foundation/American Heart Association Task Force on Practice Guidelines. J Am Coll Cardiol 62: 147-239.

2. Biondi B (2012) Mechanisms in endocrinology: Heart failure and thyroid dysfunction. Eur J Endocrinol 167: 609-618.

3. Gerdes AM, Iervasi G (2010) Thyroid replacement therapy and heart failure. Circulation 122: 385-393.

4. Rodondi N, Bauer DC, Cappola AR, Cornuz J, Robbins J, et al. (2008) Subclinical thyroid dysfunction, cardiac function, and the risk of heart failure. The Cardiovascular Health study. J Am Coll Cardiol 52: 1152-1159.

5. Vanderpump MP (2011) The epidemiology of thyroid disease. Br Med Bull 99: 39-51.

6. Tunbridge WM, Evered DC, Hall R, Appleton D, Brewis M, et al. (1997) The spectrum of thyroid disease in a community: the Whickham survey. Clin Endocrinol (Oxf) 7: 481-493.

7. Canaris GJ, Manowitz NR, Mayor G, Ridgway EC (2000) The Colorado thyroid disease prevalence study. Arch Intern Med 160: 526-534.

8. Aoki Y, Belin RM, Clickner R, Jeffries R, Phillips L, et al. (2007) Serum TSH and total T4 in the United States population and their association with participant characteristics: National Health and Nutrition Examination Survey (NHANES 1999-2002). Thyroid 17: 1211-1223.

9. Parle JV, Franklyn JA, Cross KW, Jones SC, Sheppard MC, et al. (1991) Prevalence and follow-up of abnormal thyrotrophin (TSH) concentrations in the elderly in the United Kingdom. Clin Endocrinol (Oxf) 34: 77-83.

10. Hunt SA, Abraham WT, Chin MH, Feldman AM, Francis GS, et al. (2005) ACC/AHA 2005 Guideline Update for the Diagnosis and Management of Chronic Heart Failure in the Adult: a report of the American College of Cardiology/American Heart Association Task Force on Practice Guidelines (Writing Committee to Update the 2001 Guidelines for the Evaluation and Management of Heart Failure): Developed in collaboration with the American College of Chest Physicians and the International Society for Heart and Lung Transplantation: endorsed by the Heart Rhythm Society. Circulation 112: 154-235.

11. Cowie MR, Mosterd A, Wood DA, Deckers JW, Poole-Wilson PA, et al. (1997) The epidemiology of heart failure. Eur Heart J 18: 208-225

12. Roth GA, Forouzanfar MH, Moran AE, Barber R, Nguyen G, et al. (2015) Demographic and epidemiologic drivers of global cardiovascular mortality. N Engl J Med 372: 1333-1341.

13. Levy D, Kenchaiah S, Larson MG, Benjamin EJ, Kupka MJ, et al. (2002) Longterm trends in the incidence of and survival with heart failure. N Engl J Med 347: 1397-1402.

14. Gerber $Y$, Weston SA, Redfield MM, Chamberlain AM, Manemann SM, et al (2015) A contemporary appraisal of the heart failure epidemic in Olmsted County, Minnesota, 2000 to 2010. JAMA Intern Med 175: 996-1004.

15. Bahrami H, Kronmal R, Bluemke DA, Olson J, Shea S, et al. (2008) Differences in the incidence of congestive heart failure by ethnicity: the multi-ethnic study of atherosclerosis. Arch Intern Med 168: 2138-2145. 
Citation: Francois J, Al-Sadawi M, Casillas J, Botti E, Soni L, et al. (2020) Hypothyroidism and Heart Failure: Epidemiology, Pathogenetic Mechanisms \& Therapeutic Rationale. Int J Clin Res Trials 5: 146. doi: https://doi.org/10.15344/2456-8007/2020/146

Page 5 of 5

16. Hunt SA, Abraham WT, Chin MH, Feldman AM, Francis GS, et al. (2009) 2009 Focused update incorporated into the ACC/AHA 2005 Guidelines fo the Diagnosis and Management of Heart Failure in Adults A Report of the American College of Cardiology Foundation/American Heart Association Task Force on Practice Guidelines Developed in Collaboration With the International Society for Heart and Lung Transplantation. J Am Coll Cardio 53: 1-90.

17. Galli E, Pingitore A, Iervasi G (2010) The role of thyroid hormone in the pathophysiology of heart failure: clinical evidence. Heart Fail Rev 15: 155169.

18. Bielecka-Dabrowa A, Godoy B, Suzuki T, Banach M, von Haehling $\mathrm{S}$, et al. (2019) Subclinical hypothyroidism and the development of heart failure: an overview of risk and effects on cardiac function. Clin Res Cardiol 108: 225-233.

19. Bianco AC, Salvatore D, Gereben B, Berry MJ, Larsen PR, et al. (2002) Biochemistry, cellular and molecular biology, and physiological roles of the iodothyronine selenodeiodinases. Endocr Rev 23: 38-89.

20. Klein I, Danzi S (2007) Thyroid disease and the heart. Circulation 116: 1725 1735.

21. Fazio S, Palmieri EA, Lombardi G, Biondi B (2004) Effects of thyroid hormone on the cardiovascular system. Recent Prog Horm Res 59: 31-50.

22. Liu Y, Xia X, Fondell JD, Yen PM (2006) Thyroid hormone-regulated target genes have distinct patterns of coactivator recruitment and histone acetylation. Mol Endocrinol 20: 483-490.

23. Davis PJ, Leonard JL, Davis FB (2008) Mechanisms of nongenomic actions of thyroid hormone. Front Neuroendocrinol 29: 211-218.

24. Ladenson PW, Sherman SI, Baughman KL, Ray PE, Feldman AM, et al. (1992) Reversible alterations in myocardial gene expression in a young man with dilated cardiomyopathy and hypothyroidism. Proc Natl Acad Sci USA 89: 5251-5255.

25. Taddei S, Caraccio N, Virdis A, Dardano A, Versari D, et al. (2003) Impaired endothelium-dependent vasodilatation in subclinical hypothyroidism: beneficial effect of levothyroxine therapy. J Clin Endocrinol Metab 88: 3731 3737.

26. Klein I, Ojamaa K (2001) Thyroid hormone and the cardiovascular system. N Engl J Med 344: 501-509.

27. Ojamaa K, Klemperer JD, Klein I (1996) Acute effects of thyroid hormone on vascular smooth muscle. Thyroid 6: 505-512.

28. Ojamaa K, Sabet A, Kenessey A, Shenoy R, Klein I, et al. (1999) Regulation of rat cardiac Kv1.5 gene expression by thyroid hormone is rapid and chamber specific. Endocrinology 140: 3170-3176.

29. Gick GG, Melikian J, Ismail-Beigi F (1990) Thyroidal enhancement of rat myocardial $\mathrm{Na}$, K-ATPase: preferential expression of alpha 2 activity and mRNA abundance. J Membr Biol 115: 273-282.

30. Kandan SR, Saha M (2012) Severe primary hypothyroidism presenting with torsades de pointes. BMJ Case Rep.

31. Liu Z, Gerdes AM (1990) Influence of hypothyroidism and the reversal of hypothyroidism on hemodynamics and cell size in the adult rat heart. J Mol Cell Cardiol 22: 1339-1348.

32. Udovcic M, Pena RH, Patham B, Tabatabai L, Kansara A, et al. (2017) Hypothyroidism and the Heart. Methodist Debakey Cardiovasc J 13: 55-59.

33. Khochtali I, Hamza N, Harzallah O, Hamdi S, Saad J, et al. (2011) Reversible dilated cardiomyopathy caused by hypothyroidism. Int Arch Med 4: 20

34. Somwaru LL, Arnold AM, Joshi N, Fried LP, Cappola AR, et al. (2009) High frequency of and factors associated with thyroid hormone overreplacement and under-replacement in men and women aged 65 and over J Clin Endocrinol Metab 94: 1342-1345.

35. Cappola AR, Fried LP, Arnold AM, Danese MD, Kuller LH, et al. (2006) Thyroid status, cardiovascular risk, and mortality in older adults. JAMA 295: 1033-1041.

36. Vargas-Uricoechea H, Bonelo-Perdomo A (2017) Thyroid Dysfunction and Heart Failure: Mechanisms and Associations. Curr Heart Fail Rep 14: 48-58.

37. Gerdes AM (2015) Restoration of thyroid hormone balance: a game change in the treatment of heart failure? Am J Physiol Heart Circ Physiol 308: 1-10.

38. Rodondi N, Newman AB, Vittinghoff E, Rekeneire N, Satterfield $S$, et al Subclinical hypothyroidism and the risk of heart failure, other cardiovascular events, and death. Arch Intern Med 165: 2460-2466.
39. Nanchen D, Gussekloo J, Westendorp RG, Stott DJ, Jukema JW, et al. (2012) Subclinical thyroid dysfunction and the risk of heart failure in older persons at high cardiovascular risk. J Clin Endocrinol Metab 97: 852-861.

40. Adrees M, Gibney J, El-Saeity N, Boran G (2009) Effects of 18 months of L-T4 replacement in women with subclinical hypothyroidism. Clin Endocrinol (Oxf) 71: 298-303.

41. Fadeyev VV, Sytch J, Kalashnikov V, Rojtman A, Syrkin A, et al. (2006) Levothyroxine replacement therapy in patients with subclinical hypothyroidism and coronary artery disease. Endocr Pract 12: 5-17.

42. Pearce SH, Brabant G, Duntas LH, Monzani F, Peeters RP, et al. (2013) 2013 ETA Guideline: Management of Subclinical Hypothyroidism. Eur Thyroid J 2: $215-228$.

43. Biondi B, Fazio S, Palmieri EA, Carella C, Panza N, et al. (1999) Left ventricular diastolic dysfunction in patients with subclinical hypothyroidism. J Clin Endocrinol Metab 84: 2064-2067.

44. Hak AE, Pols HA, Visser TJ, Drexhage HA, Hofman A, et al. (2000) Subclinical hypothyroidism is an independent risk factor for atherosclerosis and myocardial infarction in elderly women: the Rotterdam Study. Ann Intern Med 132: 270-278.

45. Redford C, Vaidya B (2017) Subclinical hypothyroidism: Should we treat? Post Reprod Health 23: 55-62.

46. Baumgartner C, Blum MR, Rodondi N (2014) Subclinical hypothyroidism summary of evidence in 2014. Swiss Med Wkly 144: 14058

47. Jabbar A, Pingitore A, Pearce SH, Zaman A, Iervasi G, et al. (2017) Thyroid hormones and cardiovascular disease. Nat Rev Cardiol 14: 39-55. 